\title{
AL PROGRESO EN LA FORMACIÓN DE CIUDADANOS EFICIENTES: EDUCACIÓN Y SOCIEDAD EN COSTA RICA EN 1930
}

\section{PROGRESS IN THE FORMATION OF EFFICIENT CITIZENS: EDUCATION AND SOCIETY IN COSTA RICA IN 1930}

\author{
Javier Agüero García *
}

RESUMEN

\begin{abstract}
En el presente artículo se aborda una historia de la educación a partir del análisis del libro de texto de educación cívica escrito por Elías Leiva: La educación del ciudadano completo, publicado en el primer tercio del siglo xx. Se analiza la educación desde la óptica social, el papel de la escuela como centro de instrucción y de convivencia; las familias en su entorno socioeconómico y el fortalecimiento de los valores ciudadanos y nacionales. Se trata de caracterizar la pretensión del autor en cuanto a crear una ciudadanía alfabetizada, obediente del orden establecido y principalmente, capaz de repudiar los vicios como el alcoholismo y la herencia indígena.
\end{abstract}

PALABRAS CLAVE: COSTA RICA * HISTORIA DE LA EDUCACIÓN * EDUCACIÓN CÍVICA * SOCIEDAD * CIUDADANÍA

\section{ABSTRACT}

In this article, a history of education is addressed through the analysis of textbook written by Elias Leiva: La educación del ciudadano completo (Education of full citizen), published in the early 20th Century. From social perspectives, is analyzed the role of the school as a center of education and coexistence, families in their socio-economic environment and the empowerment of citizens and national values. The author claim characterized in terms of creating a literate citizen, obedient of the established order and mainly, able to repudiate vices like alcoholism and Indian heritage.

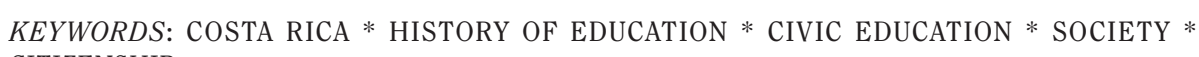

Escuela de Estudios Generales de la Universidad de Costa Rica (UCR).

jav_aguero@hotmail.com 


\section{INTRODUCCIÓN}

La perspectiva de la historia de la educación contribuye a comprender las características de la sociedad porque el acto de enseñar, aparte de incorporar los elementos propios del currículo formal de los contenidos, está inmerso en un contexto social, el cual por un lado, obedece a una política educativa o marco institucional y por el otro, incluye también a los destinatarios, quienes reciben las clases en un entorno comunal $y$ familiar.

En Costa Rica, el enfoque de la educación encaminado por una historia social se puede encontrar en el abordaje de algunas temáticas como: la formación de los docentes en el último tercio del siglo xix, durante los tiempos de la Reforma de Mauro Fernández (Rojas, 2012) y en la instrucción de las señoritas a principios en las primeras décadas del siglo xx (Palmer, 2003); entre otros autores. Ambos estudios se inscriben en una corriente historiográfica que pretende brindar al lector interesado en conocer más allá de la visión institucional, una perspectiva capaz de ofrecer una explicación del vínculo entre lo dispuesto por las autoridades y el entorno humano de aplicación de estas medidas.

Dentro de esta óptica, se pretenden identificar los indicios necesarios para dilucidar que la educación es ante todo un asunto eminentemente social. Su naturaleza no se puede abstraer de las decisiones $y$ de las acciones propias de una sociedad que tiene deseos, esperanzas y también un modelo preestablecido para la formación de individuos con un cierto perfil por difundir, diseñado desde la época de los liberales. Esto en virtud de que la educación como práctica socializa al individuo con el entorno; de tal manera que sus contenidos $y$ la forma de concebir el mundo se transforma en elementos esenciales en el imaginario colectivo.

En una dimensión más amplia, el aparato educativo a través de la extensión de las escuelas primarias, basado en el principio ilustrado del perfeccionamiento de la sociedad, es el llamado a realizar esta transformación que aspira a llegar al ideal supremo del progreso mediante la defensa a ultranza del statu quo, tal y como lo señala Carmagnani (1984) en el macrocontexto de Latinoamérica. El ansiado orden se alcanza en el momento en que los dicentes sean capaces de reconocer las diferentes funciones del Estado. En este caso específico, la Educación Cívica es concebida por los autores de la época como el conjunto de normas necesarias para la sana convivencia.

Por esta razón, en el presente artículo se analiza el texto La educación del ciudadano completo del autor Elías Leiva (1874-1936), uno de los intelectuales vinculados a la educación en sus papeles como presentador de una de las obras de Luis F. González F. (Quesada, 2001: 308) y como director del Liceo de Costa Rica. En el criterio de Justo A. Facio, Leiva además de ser un connotado jurisconsulto, es además un amplio conocedor de la formación ciudadana. Una "noble asignatura" de imperioso conocimiento entre las generaciones más jóvenes en una época en que es de vital importancia señalar las responsabilidades de quien ostenta el título de ciudadano. Para J. A. Facio, esta obra es por sus méritos una "Nueva Cartilla Cívica", desde donde brotan los más nobles valores que constituyen una auténtica cátedra de civismo (Leiva, 1933: 7-8).

La obra fue publicada en 1929 y su pertinencia es reconocida por Facio, puesto que viene a llenar un espacio de gran importancia en el conocimiento de la asignatura que tiene el cometido de inculcar las reglas y normas, susceptibles de ser difundidas mediante la publicación de los libros de texto. Asimismo, el tema de la funcionalidad de las obras didácticas es uno de los aspectos contenidos en el plan de reforma del ministro Luis Dobles Segreda. Durante esta coyuntura, se publican obras temáticas dirigidas a los docentes en varias materias, entre ellas, las referidas a la Educación Cívica. La educación del ciudadano completo es una de esas guías, junto a otra escrita por Ricardo Jiménez (Salas, 1999: 92-93).

La interrogante central que guía este escrito es cuál es el modelo de ciudadano propuesto por Elías Leiva en su texto. El orden de la exposición a seguir en este escrito es: a) el papel de la educación y de la escuela en cuanto a lo esperado como institución y como comunidad educativa en su conjunto, b) la familia y su entorno social en que se inserta el modelo a enseñar $y$ a practicar, $y$ c) los patrones de ciudadanía 
$y$ de nación propuestos para lograr crear un prototipo de ciudadano específico.

\section{LA EDUCACIÓN Y EL PAPEL DE LA ESCUELA}

En el sentido institucional, el papel de la escuela ha sido ampliamente tratado desde diferentes estudios como el de Fischel (1990), en el cual se reconoce la expansión del aparato educativo a nivel de primaria, en cuanto a su cobertura progresiva desde la década de los 80 del siglo xix. De igual manera, el texto de Leiva confiere importancia al proceso de fundación de escuelas, además aborda la organización del aparato educativo en una secretaría que paulativamente, centraliza sus funciones a partir de los tiempos de Mauro Fernández. Según E. Leiva: "la enseñanza oficial que se caracteriza por ser gratuita y obligatoria, va modelando el carácter nacional, en el sentido democrático y formando generaciones cada vez más virtuosas y más próximas al tipo de perfección" (1933: 57).

Posteriormente, se dirige al análisis de una realidad más amplia, al describir las diferentes partes en que está organizado el Estado: los poderes de la República y sus secretarías. Se nota en el esbozo de esta estructura, una similitud con lo identificado por Quesada a propósito del análisis del inicio de la modernidad política propuesto en el libro: Educación y ciudadanía en Costa Rica de 1810 a 1821 (2007), referido a la época de la independencia. En el criterio de Leiva se reconoce el valor de la Constitución Política como piedra angular que sostiene el ordenamiento jurídico. La enseñanza sobre estos temas es fundamental para lograr el reconocimiento de los órganos que velan por el orden social.

De esta manera, las obligaciones de los docentes $y$ de los estudiantes son un tema inherente a la vida escolar. En cuanto a los últimos, se señalan tres prohibiciones:

$\diamond \quad$ La envidia se señala como la primera razón que socava la convivencia social; es un "vicio feo $y$ repugnante que a veces puede conducir a los excesos más deplorables" (Leiva, 1933: 63).

$\diamond \quad$ La codicia es el segundo de los defectos a combatir, en razón de que solo se puede permitir "cuando tiene por objeto el querer saber más que los otros para sobrepujarlos, para tener las mejores notas" (Leiva, 1933: 62).

$\diamond \quad$ El tercer defecto es la avaricia, la cual atenta contra el ambiente de unión en la escuela, dado que algunos se afligen con la superioridad de los demás.

Por otro lado, los docentes tienen sus obligaciones. Posiblemente, la más importante radica en el plano afectivo, debido a que los estudiantes son "sus hijos espirituales" (Leiva, 1933: 61). Su responsabilidad no es suficiente con solo transmitir conocimientos, pues debe ser ante todo una persona abnegada con "espíritu de sacrificio (...) en el ejercicio de su apostolado" (ibid.).

Esta noble función tiene pleno sentido en el momento en que se le confiere ser una figura activa en la vida nacional "como exponente de la cultura, factor del progreso y obrero del taller en que se están formando los futuros ciudadanos de la República" (1933: 62). Se confiere entonces al docente, un alto estatus intelectual porque accede sin intermediarios del saber que engrandece $y$ distingue a la gente ilustrada. Además, se coloca como un vector capaz de sacar a la sociedad del oscurantismo por medio del progreso y finalmente, es el más noble de los servidores: un obrero que con su labor abnegada perfila las mentes $y$ los comportamientos de los estudiantes a semejanza del diseño refinado de las diferentes piezas que conforman un engranaje perfecto.

Desde esta perspectiva, el maestro es una figura clave en la fragua de la ciudadanía considerando que sus labores van más allá de la transferencia del conocimiento. Es la mano derecha de la política estatal en la tarea de formar ciudadanos. Además, la formación de la ciudadanía no se podría entender en este escenario social, al margen de la tarea encomiable de la educación: preparar para la convivencia en sociedad y para el mundo laboral.

Sin embargo, la preocupación del autor se dirige a que los temas anteriores no se pueden aplicar en la vida ciudadana porque hay todavía un sector de la sociedad analfabeta. Pese a los resultados obtenidos por la llegada de la escuela a los diferentes pueblos a más de 30 años después de la Reforma Educativa, el 
analfabetismo es desde la perspectiva pragmática por Leiva, un importante indicio de retraso social porque:

... los analfabetas no son únicamente un obstáculo para que la cultura se defina por todas partes; los analfabetas carecen también de los instrumentos necesarios para labrar su propia dicha (...). Sacarlos de ese estado es obra de cristianos y el mejor modo de hacerlo es ofrecerles la oportunidad de que se eduquen $y$ se instruyan (Leiva, 1933: 95-96).

El combate contra el analfabetismo es una labor primordial de la sociedad; es una "campaña de salvación pública" ya que en su conjunto se les consideraba "verdaderos enfermos" e incluso, este segmento de la población comparte el lugar nada deseable del resto de los vicios que más dañan a la comunidad. Luchar en contra de estas patologías sociales es en esencia la labor formativa de la escuela (Leiva, 1933).

Para llevar a cabo esta labor, Leiva revisa la organización institucional de la enseñanza oficial, desde la secretaría del ramo hasta los centros educativos, pero el énfasis está puesto sobre todo en librar esta guerra sin cuartel contra este flagelo de la ignorancia. Además, le asigna a la escuela el papel patriótico mediante el respeto a la autoridad $y$ al correcto festejo de las efemérides. En este espacio reducido se construye la patria, la escuela es una pequeña patria, una pequeña república. Es el medio por excelencia de la construcción del interés supremo de la convivencia.

Entorno a la celebración del Día de la Raza, el texto agrega que es "una fiesta que sirve para exteriorizar el sentimiento de adhesión y simpatía a la madre España y la sociedad de los países y naciones hispanoamericanas en defensa de los prestigios de la raza" (Leiva, 1933:75).

En criterio del pensamiento liberal, la admiración de las hazañas de los héroes como modelos a imitar también forma parte del cometido de la escuela, pues deben ser recordadas las figuras como la del almirante Cristóbal Colón y la Campaña Nacional contra los filibusteros. Esta última acción, digna de ser celebrada con orgullo y pomposidad, al igual que lo hace ver Quesada, en relación al Clarín Patriótico para el siglo xix (Quesada, 2006). La conmemoración más reciente para los días en que se escribe $L a$ formación del ciudadano completo, el autor destaca la gesta patriótica realizada por el educador Marcelino García F. cuando entregó su vida por una causa justa. Todos estos actos heroicos deben ser recordados con admiración en los planteles escolares.

Además de las efemérides de su respectiva celebración, la escuela - en el criterio de Leiva - debe preparar para la adultez, el trabajo y la formación del carácter. Se concibe así que “... un niño es un aprendiz de hombre útil, no es una flor como se ha dicho tantas veces, es una fuente que aguarda su sazón” (1933: 88).

Estas palabras proceden de una lectura de Pedro Palacios incorporada por el autor en su libro. Se nota claramente que entre la niñez y la vida adulta no hay ninguna etapa intermedia, aspecto que probablemente se asocia a la temprana edad en que los niños se incorporan a las labores familiares propias de la adultez. Es una época en que la educación secundaria era muy limitada en cuanto a su cobertura (Quesada, 2003: 25).

Además, el plantel de enseñanza educa para el trabajo, pues el autor basado en el sistema estadounidense, considera esta labor como una virtud que debe ser inculcada desde la etapa escolar. En su criterio, de ser exitosa esta tarea, entonces Costa Rica seguiría los pasos de Henry Ford, la más grande de las personalidades industriales (Leiva, 1933: 164).

Por otro lado, el deber patriótico es considerado necesario para enseñar a los discentes acerca de la obligatoriedad de respetar tanto el estandarte como la bandera nacional, al grado de que “... los niños deberán negar su estandarte y su bandera para ciertos festejos populares indignos de gentes civilizadas" (Leiva, 1933: 69).

En esta tarea de llevar la civilización, resultan censurables aquellas diversiones en que los animales sean los objetos de algún tipo de agresión, debido al interés utilitario de esas criaturas:

... muchos de esos animales nos brindan generosamente su leche, otros su carne, su trabajo y su compañía; algunos como los pájaros, nos alegran con su canto $y$ con la belleza de su plumaje. ¿Por qué 
entonces causarles sufrimientos que van a disminuir la utilidad que nos prestan? (Leiva, 1933: 100).

De ahí entonces que se declare la "... guerra a las flechas, guerra al chuzo de hierro; guerra a las corridas de toros, guerra a las peleas de gallos y a las cargas excesivas de los animales que transitan por ellos" (Leiva, 1933: 101).

Los festejos populares conformados por el conjunto de tradiciones de la cultura popular con presencia de animales y de alcohol, son adjetivados como indignos y vulgares. Se les mira con reprobación por parte de la misión civilizadora de los gobernantes.

Para reforzar estos contenidos antes analizados, el libro escrito por Leiva incluye varias lecturas breves de diversos autores acerca de temas como los deberes para con los demás y para con la patria, los derechos otorgados por el ordenamiento jurídico y las características de la vida política en democracia.

CUADRO 1

LECTURAS INCLUIDAS EN EL TEXTO LA FORMACIÓN DEL CIUDADANO COMPLETO

\begin{tabular}{|c|c|c|}
\hline TÍTULO DE LA LECTURA & AUTOR & $\begin{array}{l}\text { CONTENIDO DESEADO } \\
\text { PARA QUE LOS INDIVIDUOS... }\end{array}$ \\
\hline $\begin{array}{l}\text { El porvenir de la patria depende de } \\
\text { la escuela }\end{array}$ & José H. Figueroa & $\begin{array}{l}\text {-Adquieran conocimientos. } \\
\text {-Renuncien a la pereza que produce la barbarie de la } \\
\text { humanidad. } \\
\text {-Se apliquen a los estudios y cumplan con los } \\
\text { deberes ciudadanos. }\end{array}$ \\
\hline La constancia & Oscar Wilde & $\begin{array}{l}\text {-Triunfen en la vida. } \\
\text {-Sean constantes. } \\
\text {-Puedan ser santos mediante la constancia. }\end{array}$ \\
\hline La escuela debe producir & Roberto Brenes Mesén & $\begin{array}{l}\text {-Produzcan a partir de sus capacidades intelectuales. } \\
\text { - Puedan producir si cuentan en sus escuelas de } \\
\text { máquinas y talleres. } \\
\text {-Puedan ser útiles a la comunidad. }\end{array}$ \\
\hline Tener carácter & Pedro Palacios & $\begin{array}{l}\text {-Tengan iniciativa. } \\
\text {-Posean las armas para hacerle frente a la vida. } \\
\text {-Sean independientes. }\end{array}$ \\
\hline Ser sincero & Emilie Zola & $\begin{array}{l}\text {-No sean hipócritas. } \\
\text {-Siempre hagan uso de la verdad. } \\
\text {-Triunfen. }\end{array}$ \\
\hline Nuestro carácter nacional & Antonio Zambrana & $\begin{array}{l}\text {-Sean cristianos. } \\
\text {-Sean demócratas. } \\
\text {-Sean fraternos. }\end{array}$ \\
\hline Almafuerte & Pedro Palacios & $\begin{array}{l}\text {-Sean como un árbol en crecimiento. } \\
\text {-Sean aprendices de hombres adultos. } \\
\text {-Sean bondadosos. }\end{array}$ \\
\hline Como el molino & Amado Nervo & $\begin{array}{l}\text {-Sean luminosos. } \\
\text {-Sean bondadosos. } \\
\text {-Sean instrumentos para la fertilidad. }\end{array}$ \\
\hline Verdadero patriotismo & J. Barni & $\begin{array}{l}\text {-Sean patriotas. } \\
\text {-Amen a la patria. } \\
\text {-Repudien la injusticia y la barbarie. }\end{array}$ \\
\hline La alegría de trabajar & Modesto Martínez & $\begin{array}{l}\text {-Puedan producir, acumular y distribuir. } \\
\text {-Puedan emular fordismo. } \\
\text {-Trabajen sobre todo en la agricultura. }\end{array}$ \\
\hline
\end{tabular}

Nota: Por carecer de relación directa con el contenido y formato de este cuadro, se excluye la lectura "La Bandera de CR" de Clara R. Cabrera (Leiva, 1993).

Fuente: Leiva, 1933: 58, 67- 68,76, 78, 80, 87-88, 106, 110 y 163. 
Indudablemente que estos fragmentos de lecturas de los autores anteriores apuntan hacia la elaboración de un perfil deseado para los futuros ciudadanos, de ahí que los diferentes materiales se aplican al mundo escolar. Por tanto, la escuela es el espacio idóneo para inculcar y ensayar los diferentes valores que van desde la siembra de la huerta hasta la venta de la cosecha; desde la confección de alguna prenda de vestir hasta su utilización por parte de algún miembro de la familia $y$ desde el respeto por la autoridad del maestro hasta el sometimiento pleno al sistema sociopolítico imperante.

\section{LAS FAMILIAS Y SU ENTORNO}

¿Cuál es el modelo de familia, de los hijos $y$ de la condición de la mujer contenidos en las ideas expuestas por Leiva? La familia es considerada como la patria en pequeño, dentro de esta el padre es la luz del hogar que regula $y$ pone orden a los comportamientos. Por tanto, no es de extrañar que se abogue en favor del patrón patriarcal estudiado ampliamente por Rodríguez (2003), cuando señala que los roles tradicionales conforman una realidad en sus prácticas al interior de las unidades familiares y que además estas características se enmarcan en una tendencia de larga duración, las cuales van a encontrar su punto de inflexión hacia mediados del siglo Xx, cuando al fin se le otorga el derecho al voto a la mujer.

De acuerdo a la visión prevaleciente, la mujer ocupa dos lugares: como esposa y como hija. Como cónyuge y compañera debe dedicarse a las ocupaciones del aseo y disponer de la casa en cuanto a decidir el menú diario. Además, debe estar cerca de sus hijos y acompañar a su marido $y$ al resto de la prole frente a la adversidad, para así aliviar la desgracia (Leiva, 1933: 50-51).

Por su lado, la mujer como hija debe ser "juiciosa y ordenada, es la mejor compañera de su madre y si además es hacendosa, amable, dócil y buena, tendrá que ser a no dudarlo, el mejor adorno del hogar y el orgullo de sus padres" (Leiva, 1933: 51).

Según este modelo a emular, se considera que en el hogar, las mujeres cultas pueden proyectar la luz de sus ideales sobre las escabrosidades del camino. Sin embargo, esta visión tan estereotipada de la mujer contrasta con las condiciones de la vida de las obreras y de las pobres que no encajan con el modelo hegemónico. Su misma precariedad hace que habiten en sitios hacinados y malsanos (Mora, 1994). Ante esta realidad, Leiva reconoce al menos que "algunas madres" de los estudiantes ven imposibilidades para asistir a las presentaciones culturales de sus hijos:

Las madres van a la escuela a escuchar aquellas voces infantiles que les hablan de su amor y de sus más puros afectos, $y$ para las que no puedan asistir por la distancia, por sus enfermedades o su pobreza existe la franquicia telegráfica en las oficinas del Estado, a fin de que puedan transmitir telegráficamente todos los bellos pensamientos que en ese día tienen los niños para los seres queridos que les han dado el ser... (Leiva, 1933: 74).

Las condiciones de higiene $y$ de salud son motivo de interés por parte del Estado Liberal Reformado, preocupado de velar por el aumento de la población, que a su vez era esencial para garantizar la reproducción de un factor productivo: la suficiente mano de obra para la agroexportación. Es indispensable, de acuerdo a la política pública imperante, que las gentes cuenten con buena salud para trabajar, tanto en el campo como en los oficios urbanos (Botey, 2013).

Además, el autor hace un llamado a los asuntos estéticos y ornamentales relacionados con adornar las entradas de las viviendas con plantas y a luchar en contra del polvo que se metía en las casas. Sin embargo, es menester señalar que en concordancia con lo señalado por Cerdas (1995) y Elizondo (2005), más allá de las nubes de polvo y de la necesidad de colocar plantas en la entrada de las casas, subyace una realidad social más crítica que trasciende lo estético, asociada indiscutiblemente al déficit habitacional $y$ a las condiciones precarias e insalubres que tienen muchas de las viviendas.

De la amplia gama de problemáticas sociales, la higienización es abordada con rigor en el manual de Leiva: es necesario erradicar cierto tipo de prácticas no correctas y velar por darle mantenimiento adecuado a los caños 
$y$ las letrinas, entre otros. De lo contrario, serían los focos de enfermedades que en suma se convierten en verdaderas amenazas para los habitantes:

Al ciudadano verdadero se le ofrece aquí un vasto campo a sus iniciativas y esfuerzos por el bien público. Para el saneamiento de su vecindario debe comenzar por la disecación del pantano, el drenaje de su terreno, la construcción completa de su desagüe, de su cloaca, el aseo de su patio, de su jardín y de su excusado (Leiva, 1933: 38).

Para Leiva, las enfermedades tienen también un carácter social, de ahí que la conducta esperada del ciudadano completo sea la de luchar para evitar la propagación de los padecimientos:

... no se necesitará por cierto mucho esfuerzo para hacerles comprender que cuando una enfermedad llega a nuestro pueblo con carácter de epidemia, hace sus mayores estragos en aquellos barrios donde no hay excusados o letrinas y en donde, en fin los vecinos no se cuidan de que las aguas destinadas al consumo estén limpias... (1933: 30).

En el rubro de las enfermedades, la tuberculosis $y$ la anquilostomiasis se consideran los principales peligros que ponían en riesgo a la población. En el caso del segundo padecimiento, la solución consistía en dotar a los habitantes de calzado; no obstante, el autor es enfático en afirmar que el peligro que afectaba la población era de índole eminentemente social, por ejemplo: el alcoholismo, que incluso supera los estragos de otras enfermedades porque: "los efectos del alcoholismo sobre la prole son, si se quiere más temibles que los de la heredo-tuberculosis" (Leiva, 1933: 41). Más adelante se refiere a otros efectos del alcoholismo:

La sola enumeración de ellos causa el más profundo horror: tuberculosis, neurastenia, histerismo, epilepsia, mortalidad infantil, prostitución, y todas las formas del libertinaje, locura $y$ todas las formas de la degeneración mental, homicidio y todas las formas de delincuencia (ibid.).

Así mismo, para hacerle frente a este flagelo, se formulan dos soluciones: a) la propaganda en contra de este vicio y b) las medidas represivas como el castigo a los ebrios junto con la prohibición en contra de expedir la bebida. No obstante, la mejor de las medidas se le encomienda a las mujeres y a la niñez: "es justo esperar que la campaña contra el alcohol tenga sus mejores aliados en las mujeres y los niños, pues las esposas y los hijos del alcohólico son los verdaderas víctimas del depreciable vicio" (Leiva, 1933: 42).

Como se vio con antelación, para Leiva, el vicio del alcoholismo está íntimamente vinculado a la diversión. En su criterio, las fiestas adjetivadas como cívicas, que en ocasiones incorporan el alcohol, deben ser cuestionadas en el sentido siguiente: “Podrán llamarse fiestas cívicas a las lidias de toros o a las diversiones populares en que juegan su papel principal los vicios y el alcohol?" (1933: 75).

Por esta razón, se da un claro interés de desterrar el consumo de alcohol de las esferas relacionadas a las fiestas (v. g. patrias $y$ de pueblo) y también de las populares. Existe un constante llamado de atención en relación al consumo de alcohol y en la misma reglamentación de las fiestas y de los turnos. Sin duda alguna, todas eran medidas conformantes del ejercicio del control social por parte del Estado (Enríquez, 1998: 180). De acuerdo con las autoridades, el esparcimiento queda circunscrito a espacios sin consumo de la bebida.

La pobreza y la miseria también son abordadas en La educación del ciudadano completo. Se exhorta por todos los medios a que la población se desprenda de una parte de sus pertenencias para ayudar a los más necesitados. Las condiciones miserables que padecen una parte de la población son asumidas como un asunto a resolver mediante la caridad e incluso, se mira con cierto romanticismo el trabajo infantil, pues en palabras del autor, es una práctica necesaria en el seno de algunas familias, de ahí que: 
... no es despreciable tampoco el trabajo que realizan los niños en la casa, especialmente los que pertenecen a las familias pobres, que son las más numerosas entre nosotros. Es cosa que da gusto ver cómo ayudar a sus padres muchos de ellos en el oficio que les da sustento. Mientras unos van a la escuela, los otros se asocian a la faena, ayudando en aquellas operaciones que pueden ejecutar por estar al alcance de sus fuerzas $y$ de su edad... (Leiva, 1933: 51).

Para hacerle frente a la política social, los impuestos solo tienen sentido si se grava la venta de ciertos artículos con tributos. Al respecto, el texto indica lo siguiente:

...tratemos de interesar a los demás ciudadanos y al municipio a la mejora de las viviendas para los pobres, hagamos que se ponga contribución o impuesto a los vicios que, como el alcoholismo son causa, de degeneración física, para que con su producto se sostengan las instituciones de previsión social, los dispensarios anti-tuberculosis, las colonias escolares de vacaciones, el abrigo de los niños, la gota de leche, los sanatorios, etc. (Leiva, 1933: 40-41).

Se resalta que este tipo de iniciativas forman parte de la solidaridad proclamada por los mismos que en su discurso abogan en favor de la caridad, con el fin de solucionar los problemas sociales. Políticas como la gota de leche - dirigida a donar a los más necesitados-y el acto de contribuir a sufragar el gasto de las instituciones como la Cruz Roja, constituyen también un asunto dirigido a aquellos que se desprenden de algún bien en favor de los demás. Para Leiva: "hacer caridad es hacer el bien" (1933: 157).

Ante la interrogante de por qué darle una mano a los más desfavorecidos de la sociedad, Leiva proporciona dos tipos de respuestas:

a) Porque es una forma de afrontar las demandas productivas en momentos en que la mortalidad infantil acecha con el consiguiente faltante de población capaz de atender las labores agrícolas de la siembra y de la recolección de la cosecha. Como corolario de esta medida, también se destaca el interés de que a mayor producción, menor obligación estatal de atender necesidades sociales: "hacer la caridad es hacer el bien y mejorar las condiciones de vida de los demás; pero es también darle más brazos a la agricultura y a las industrias, hacer producir el país más de lo que produce, quitarle cargas al Estado $y$, en último término, beneficiarnos nosotros mismos" (1933: 157).

b) Dentro del credo de la democracia prereformada, mediante estas campañas paliativas, se busca dotar de mejores condiciones a la niñez, porque eso se traducía en la protección de la raza. En última instancia, el objetivo doble, vender la idea de preservar rasgos muy propios de la sociedad encarnados en los más pequeños $y$ es una razón para hacerle frente al peligro más evidente de la época: la mortalidad infantil.

En este contexto, ¿cómo presenta el autor las condiciones de los trabajadores? En realidad, se confiere la importancia a una acción concreta producto de la política social: la Ley de accidentes de trabajo promulgada en 1925. La función exitosa realizada por la institución encargada de administrar los seguros de accidentes de trabajo es bien ponderada por el autor: "en vista de los excelentes resultados del Banco Nacional de Seguros, nadie podrá dejar de aplaudir el establecimiento de tan benéfica institución..." (Leiva, 1933: 78).

No obstante, debe tomarse en cuenta que los desempleados por el hecho de no producir, son motivo de preocupación por parte de las autoridades $y$ aunque se indique que son pocos en cantidad para la época, son una carga para el erario. Al respecto, se dice que: "son por fortuna contados los que se sustraen a este deber, recibiendo por eso la repulsa de la sociedad, pues [ellos] son parásitos que viven a nuestras expensas o [son] los ladrones que nos arrebatan el producto de nuestro esfuerzo..." (Leiva, 1933: 162). 
Por estas razones, un libro dedicado a la formación de ciudadanos no se abstrae del contexto social en el que está inmerso. Las consecuencias de las crisis propias de los golpes ocasionados por la estructura misma de la agroexportación, son abordadas por el autor y frente a este crítico panorama lo que se ofrece es tributar más, ser más caritativo y combatir los vicios; verdaderos yerros que amenazan la vida social y económica del país.

\section{LA CIUDADANÍA Y LA NACIÓN}

La forma de definir los deberes del ciudadano se describen de esta manera: "el primero de estos deberes es la obediencia a las leyes y respeto a las autoridades constituidas (...). Su remedio estaría en combatir la ignorancia y los hábitos viciosos del pueblo..." (Leiva, 1933: 115-116).

Así, se reconoce en primer lugar, el precepto de acatar las normas y a las autoridades que rigen la sociedad por parte de los ciudadanos. Se considera el orden, como uno de los bastiones del Estado Liberal, básico en el funcionamiento del engranaje social. En un segundo lugar, se confiere a la educación un papel salvador capaz de redimir a la sociedad en su conjunto. Por medio de la educación y la civilización de los habitantes, se haría posible entrar a las sendas del progreso. Estas junto con el orden, constituyen los cimientos más sólidos del liberalismo como doctrina.

El progreso se equipara con la producción, de ahí se deduce que al Estado le interese sobremanera la exigencia de trabajar por parte de los habitantes. El autor luego de realizar un reconocimiento de las diferentes profesiones $y$ oficios en cuanto a lo producido desde diferentes espacios del mundo laboral, asigna la importancia de la colaboración de cada uno de los diferentes aportes para la riqueza nacional. Además, considera la necesidad de organización que va desde la producción en las huertas escolares hasta el éxito del Sindicato de la Leche. Así, las cajas de ahorro son un soporte $y$ un apoyo para los trabajadores en momentos de dificultad; junto con los ejemplos de mutualismo, ambos conforman modelos que deben ser imitados por el resto. Las cooperativas y la forma organizativa del emporio estadounidense de Henry Ford deberían ser los nortes a emular pues:

... hay en sus fábricas alcancías o cajas de ahorros en donde los obreros depositan semanalmente una parte de sus salarios, y cuando estos ahorros alcanzan la suma necesaria para obtener una acción, la empresa los recoge y el obrero pasa a ser así accionista de la gran fábrica... (Leiva, 1933: 172).

Según el autor, la producción necesaria para el crecimiento de las finanzas debe ir de la mano con la necesidad de pagar impuestos junto con el emprendedurismo individual y grupal. En cuanto a los tributos se reconoce que son fundamentales para alimentar la hacienda pública, los indirectos son claves para hacerle frente a los gastos del Estado. Además, exhorta que la contribución directa de los habitantes a fin de que colaboren a sufragar los gastos derivados de la edificación de las obras públicas. En este sentido: “...comencemos en nuestro propio distrito induciendo a los vecinos al pago de los detalles que proporcionan los fondos para la construcción de escuelas, apertura y composición de calles y caminos..." (Leiva, 1933: 117).

Contribuir con los detalles - montos a pagar por los habitantes en las diferentes comunidades - al igual que tributar mediante el sistema convencional, son obligaciones ciudadanas inexorables. Además, se hace un llamado para que las escuelas insistan en la necesidad imperiosa de estimular el espíritu de la iniciativa propia de los habitantes, con la finalidad de ir adelante a la acción del Estado, de esta forma: "no esperemos que todas estas obras las lleve a cabo el gobierno: adelantémonos con nuestros respectivos proyectos y sus muchas deliberaciones..." (Leiva, 1933: 66).

El ciudadano completo es aquel que vela en favor del bien público, es además solidario, emprendedor y colabora en la construcción de la infraestructura.

Asimismo, en el tema del sufragio, ¿qué opinión le merece a Leiva lo relacionado con el voto? El sistema electoral es una pieza clave de un modelo analizado por Iván Molina (2005) 
como demoperfectocracia. Término de la época acuñado por la escritora Yolanda Oreamuno en los años 30; caracterizado por el libre juego del sufragio que de alguna manera, dibuja una democracia de fachada no exenta del fraude electoral y de otros vicios (Molina, 2005: 21).

En esta misma dirección, inscritas en el ámbito formal, en las preocupaciones de Leiva relacionadas con el sufragio, destaca una esencial: la obligatoriedad de emitir el voto, siendo este el llamado fundamental a los habitantes para dar un mensaje contra el abstencionismo en favor de la participación electoral; es decir, si alguien se queda en la casa sin votar, otros deciden por quienes no asisten a las urnas (1933: 118). Además, es importante anotar que de acuerdo a la visión del autor, todas aquellas irregularidades asociadas al proceso electoral serían castigadas con la mano dura de la ley:

... como se ve, la votación es un acto muy sencillo que no requiere más que la buena voluntad del individuo para que resulte sincero $y$ honesto. Cualquier fraude o engaño que quisiéramos cometer para alterar el resultado de la votación aparecería de manifiesto y nos haría incurrir en los delitos que la misma ley se encarga de penar (Leiva, 1933: 129).

Sin embargo, tal y como lo estudia Molina, estos vicios en el ejercicio del sufragio son parte del juego de las prácticas políticas de entonces y más bien no fueron la excepción dentro de la vida sociopolítica del país. En este sentido, no es fortuito que el sistema perdiera credibilidad de los comicios ante la cantidad de acusaciones de fraude por intromisión del Ejecutivo, registradas entre 1901 y 1946 (2005: 430-431).

Como se señaló anteriormente, la discusión del voto femenino estaba en boga para la época y la visión oficial se resume en que no es conveniente otorgar el derecho al voto a la mujer. Al respecto, Leiva es consciente de las luchas sufragistas de las mujeres:

... la corriente femenina trata de llevar a la mujer a los comicios y como consecuencia al gobierno del Estado. ¿Conviene o no conviene fomentar este movimiento que es ya general en todo el mundo? (...). Es al lado de sus esposos $y$ de sus amigos, padres en donde con la influencia de su consejo sano y con la visión más clara que ellas tienen del peligro, puede hacerse sentir la capacidad cívica de la mujer... (1933: 130).

En otras palabras, la mujer está detrás y al mismo tiempo por debajo del hombre, es una pieza fundamental de la familia. Sus labores primordiales son atender a su marido $y$ hacerle frente a la crianza de los hijos, pero es considerada incapaz de ejercer derechos políticos.

En cuanto a la raza, se considera que forma parte del ser costarricense, el amor a la paz, que junto con el clima y el ambiente son características distintivas forjadoras de una identidad (Leiva, 1933: 79). Además de exaltar el espíritu no armado del país, también se destacan elementos del nacionalismo $y$ pese a que lamente la ausencia de un traje formal netamente costarricense, se llama a exaltar el "carácter nacional" basado en el aporte español por encima del autóctono: "somos una mezcla del aventurero arrogante, sufrido, austero y fanático y del indio desconfiado, manso e inconstante..." (Leiva, 1933: 79).

Además, agrega que los niños deben abrazar buenos hábitos y realizar las prácticas de los blancos, para así renunciar de una vez a todas las costumbres indígenas que son sinónimo de atraso: "hay un defecto de nuestros niños que lo es también de nuestra raza, $y$ que por tanto conviene corregir siempre; el de ser desordenados e impuntuales. El levantarse tarde, el llegar a la mesa a deshoras..." (Leiva, 1933: 55).

El costarricense blanco es una idea construida en completa oposición a los valores indígenas. Para Leiva, los habitantes autóctonos han desaparecido del país, no tanto por la mezcla con la raza blanca, sino por su falta de hábitos de higiene y su gran afición alcohólica (Leiva, 1933: 40).

El énfasis puesto en el elemento étnico como compensación de una cierta inmadurez del producto cultural de la civilización costarricense es advertido claramente por Iván Molina, cuando se refiere a la casi perfección de una 
raza blanca asumida por amplios sectores de la población a inicios del siglo xx (2010: 8-9). Se ignoran entonces los resultados de la conquista y colonización junto con las acciones del Estado Nacional, en lo que respecta al impacto devastador que tuvieron estas determinaciones sobre los habitantes autóctonos. No solo los indígenas eran vistos con los ojos de la inferioridad, otros grupos étnicos también corrían la misma suerte. Al respecto, cuando se refiere a una campaña contra las moscas, relaciona a ese insecto con las supuestas características de una cultura foránea: "la mosca a primera vista parece un insecto inofensivo. Sus costumbres domésticas, la confianza en que entra y sale de las habitaciones (...) le han valido la indiferencia casi musulmana con que la vemos acercarse hacia nosotros..." (Leiva, 1933: 33-34).

Posiblemente, la mejor manera que tiene Leiva para enfatizar aún más los rasgos de la identidad nacional, consiste en incluir en sus lecturas de apoyo, un texto de la autoría de Antonio Zambrana, connotado intelectual de origen cubano que residió en Costa Rica (Vargas, 2006: 23).

Al respecto, Zambrana no tiene reparo al referirse a lo distintivo del ser costarricense cuando afirma que: "nuestro carácter nacional. -Aquí no tenemos ni las arraigadas aristocracias ni la adoración del dólar omnipotente que pudren a Europa y a los Estados Unidos..." (Leiva, 1933: 80).

Aunque se admire el sistema de producción estadounidense, para Zambrana los elementos muy propios de Europa $y$ de la potencia del Norte, no deben ser tomados como ejemplos a imitar por parte de los costarricenses:

... para ser demócratas para ser cristianos, para llegar a serlo se entiende, nadie nos aventaja. Ser eso es lo que importa... Nuestros rencores son superficiales: nunca odiamos en firme lo cual nos viene de los indios blandos, cuasi angélicos que por aquí vivían (...). El sol que nos caldea nos hace tiernos, generosos, amigos de lo ideal, enamorados de lo sublime, soldados de lo justo y demócratas como por instinto... (Leiva, 1933: 81).
Dicho de otro modo, la identidad nacional es abordada por el texto de Leiva; sus valores a difundir e inculcar son más que evidentes: el deber de votar, un rotundo no a la participación de las mujeres en el ejercicio del sufragio y una intolerancia frente a las culturas consideradas como inferiores: la indígena y la musulmana.

\section{CONCLUSIÓN}

La utilidad del libro de texto como objeto de estudio de la historia de la educación, tiene su pertinencia porque es testigo de un pasado que reúne un cúmulo de características sociales abordadas por aquellos autores que con su pluma se dedicaron a enseñar nuevos comportamientos o bien, a cambiar los existentes. En este caso, la obra de Leiva arroja luces acerca de características de una época marcada por el interés de dotar de libros que inculcaran valores cívicos asociados a un ideal de vida por parte del resto de la población.

La educación del ciudadano completo es ante todo, un claro ejemplo del proyecto del deber ser enunciado por un autor. Su objetivo es traer a colación los aspectos medulares considerados como tareas ineludibles por ejecutar o por mejorar, en aras de construir una sociedad mejor, bajo la estela del progreso. A continuación, se esbozan los principales planteamientos de Leiva:

a) Velar por el orden de la escuela para así delimitar los comportamientos de los estudiantes e insistir en las acciones ejemplarizantes que deben asumir los maestros en el ejercicio de su apostolado.

b) Fomentar el deber cívico en los planteles de enseñanza, con el fin de servir a la patria para personas responsables e intachables. Con el entusiasmo en la entonación de los cantos patrios; acompañado por el respeto casi religioso en la celebración de las efemérides, se lograría la formación de un individuo capaz de ennoblecer los altos valores costarricenses. Esto inscrito en el proceso de invención de la Nación que iniciaron los liberales en el último tercio del siglo XIx (Molina, 2010: 132). 
c) Ante la crisis del modelo agroexportador (1914-1940) —contexto más amplio de la realidad costarricense - se hace un llamado a la necesidad imperiosa de contribuir mediante los impuestos. Solo así se podía construir un mejor país a partir de la redistribución de la riqueza. Por tanto, la educación es también un ejercicio de llamar a los costarricenses a pagar sus tributos. Además, se estima que hacer la caridad constituye una forma de atenuar las condiciones de estrechez económica que ha golpeado a los sectores más desfavorecidos de la sociedad.

d) La obligación de emitir el voto es también objeto de preocupación, en el sentido que la democracia requiere electores participativos que manifiesten su voluntad en las urnas. Sin embargo, el autor se suma al criterio prevaleciente $y$ no se reconoce que la mujer sea capaz de emitir el sufragio. Este tipo de educación cívica niega ad portas este derecho a esa mitad de la población. La mujer es de todo, desde esposa hasta madre de los hijos y desde ama de casa, hasta un objeto digno de ser mostrado por el varón. Pero claro está que no podía ser ciudadana.

e) Los males que agobian a la sociedad son también abordados por el autor, además de la desnutrición que aquejaba a la población infantil. Al igual que en el caso del hacinamiento que viven importantes sectores sociales, este tipo de problemáticas que acecha a los más pobres, debe ser atacada primordialmente, mediante una lucha en favor de la higienización, el pago de los tributos y el ejercicio de la caridad.

f) El espíritu nacional es considerado como pobre con respecto al vivido por los habitantes de otras latitudes, por la carencia de motivos externos diferenciadores. Es impostergable fortalecer los valores patrios a partir de una selección de atributos que indudablemente deben desechar los elementos indígenas. Pues solo se puede crear una nueva patria mediante la negación rotunda de los motivos autóctonos causantes del atraso y la impuntualidad, hábitos que todavía acompañan el ser costarricense; ambos son achacados a los indígenas, según el autor.

Además de los contenidos propios del currículo formal comprendido en la formación de la ciudadanía, solo queda reflexionar a partir de este análisis de la imagen de Costa Rica de los años 30:

$\diamond \quad$ Es impostergable educar al país mediante la exhortación de los valores patrios.

$\diamond \quad$ Es un país inmerso en las duras condiciones socioeconómicas, cuyos embates se manifestaron tanto en el campo como en la ciudad, propias de un período de entreguerras.

$\diamond \quad$ Es una sociedad que vive en medio de una congoja social apremiante. Por tanto, es imperioso el pago de los impuestos $y$ hacer obras de caridad.

$\diamond \quad$ Es un país en que se registran reivindicaciones de los grupos feministas; empero los sectores hegemónicos prestan oídos sordos frente a estas peticiones. Quizá el mejor ejemplo es el caso del voto femenino.

$\diamond \quad$ Es una sociedad en que se inculca desde las aulas escolares que la civilización proviene de los europeos y por consiguiente, los elementos indígenas deben ser desterrados de la memoria y de la historia.

Por último, quedaría incompleto este marco hacia la construcción de un ciudadano eficiente, si no se toma en cuenta el combate contra los vicios. Es la fórmula para salir del estado de barbarie. Por tanto, se conforma así la tríada estratégica, en pro de la consecución de tal objetivo, constituida por: a) el acatamiento del statu quo para continuar por la senda del orden; b) el fomento a la educación para así vencer al analfabetismo y a la barbarie y c) el repudio a ultranza de los vicios y de los valores indígenas. Estos tres pilares son la ruta para llegar a perfilar un ciudadano completo en medio de un contexto de un país en la coyuntura crítica. 
BIBLIOGRAFÍA

\section{FUENTE PRIMARIA IMPRESA}

Leiva, Elías (1929). La educación del ciudadano completo. 2da. edición. San José, Costa Rica: Imprenta Gutemberg, 1933.

LIBROS

Botey, Ana María. Costa Rica entre guerras: 1914-1940. San José: Costa Rica: Editorial de la Universidad de Costa Rica (EUCR), 2007.

Carmagnani, Marcelo. Estado y sociedad en América Latina, 1850-1930. Barcelona, España: Crítica, 1984.

Elizondo, William. "El problema de la vivienda, segregación y pobreza urbana en la primera mitad del siglo xx". Pobreza e historia en Costa Rica. Ronny Viales (ed.). San José, Costa Rica: Editorial de la Universidad de Costa Rica (EUCR), 2005.

Fischel, Astrid. Consenso y represión: una interpretación sociopolitica de la educación costarricense. San José, Costa Rica: Editorial Costa Rica (eucR), 1990.

Molina, Iván. Costarricense por dicha: identidad nacional y cambio cultural en Costa Rica durante los siglos xIx y $x x$. San José, Costa Rica: Editorial de la Universidad de Costa Rica (eucR), 2010.

Molina, Iván. Demoperfectocracia: la democracia pre-reformada en Costa Rica (1885-1948). Heredia, Costa Rica: Editorial de la Universidad Nacional de Costa Rica (EUNA), 2005.

Palmer, Steven. "Educando a la señoritas: formación docente, movilidad social y nacimiento del feminismo (1885-1925)". Molina, Iván y Palmer, Steven. Educando a Costa Rica: alfabetización popular, formación docente y género (1850-1950). San José, Costa Rica: euned, 2003.

Quesada, Juan Rafael. Historia de la historiografía costarricense, 1821-1940. San José, Costa Rica: eucr, 2001.
Quesada, Juan Rafael. Estado y educación en Costa Rica. Del agotamiento del liberalismo al inicio del Estado Interventor: 1914-1949. San José, Costa Rica: EucR, 2003.

Quesada, Juan Rafael. Clarín Patriótico: la guerra contra los filibusteros y la nacionalidad costarricense. Alajuela, Costa Rica: Museo Histórico Cultural Juan Santamaría-Colegio de Licenciados y Profesores, 2006.

Quesada, Juan Rafael. Educación y ciudadanía en Costa Rica de 1810 a 1821: del crepúsculo colonial al umbral de la modernidad politica. San José, Costa Rica: EucR, 2007.

Rodríguez, Eugenia. Dotar de voto político a la mujer. ¿Por qué no se aprobó el sufragio femenino en Costa Rica hasta 1949? San José, Costa Rica: Eucr, 2003.

Vargas, Armando. El doctor Zambrana. San José, Costa Rica: euned, 2006.

\section{REVISTAS IMPRESAS}

Cerdas, José Manuel. "Los obreros en la época de la manufactura: 1900-1955". Revista de Historia 31. San José, Costa Rica. Universidad de Costa Rica, enero-junio 1995: 127-162.

Mora, Virginia. "Los oficios femeninos urbanos en Costa Rica (1864-1927)". Mesoamérica 27. Plumsock Mesoamerican Studies, 1994: 127-156.

Salas, José Antonio. "La enseñanza de la historia desde el currículo". Perspectivas 2. Heredia, Costa Rica. Universidad Nacional (unA), 1999: 75-98.

TESIS

Botey, Ana María. "Los actores sociales y la construcción de las políticas de salud del Estado Liberal en Costa Rica (18501940)".[Tesis de Doctorado en Historia]. Universidad de Costa Rica, 2013. 
Enríquez, Francisco J. "Diversión pública $y$ sociabilidad en las comunidades cafetaleras de San José: el caso de Moravia (1890-1930)". [Tesis de Maestría en Historia]. Universidad de Costa Rica, 1998.

Rojas, Francisco Javier. "Historia social de la educación secundaria y de los profesores de secundaria en Costa Rica: 18691909". [Tesis de Doctorado en Historia]. Universidad de Costa Rica, 2012.

Fecha de ingreso: 20/04/2014 Fecha de aprobación: 16/09/2014 